Estudios sobre armas antiguas, arte militar $\mathrm{y}$ vida cultural en oriente y occidente

XL (2020), pp. 113-131

ISSN: 0436-029X; eISSN: 1988-4168

https://doi.org/10.3989/gladius.2020.05

\title{
LA GUERRA EN LOS TEXTOS NORMATIVOS DE LAS ÓRDENES MILITARES DE CALATRAVA Y SANTIAGO*
}

\author{
THE WAR IN THE RULES OF THE MILITARY ORDERS \\ OF CALATRAVA AND SANTIAGO
}

POR

\section{J. Santiago Palacios Ontalva**}

\section{RESUMEN - ABSTRACT}

La literatura reglar generada por las órdenes militares de Calatrava y Santiago contiene información relevante para estudiar muchos aspectos de su organización, entre ellos algunos que nos explican su vínculo fundamental con la guerra. Este trabajo busca realizar un estudio comparativo de ese corpus textual formado por reglas, estatutos, definiciones, actas capitulares y establecimientos de las dos principales órdenes hispanas, para conocer mejor el carisma bélico que estas instituciones tuvieron. Por otro lado, se podrán trazar paralelos o divergencias entre una y otra, además de ayudarnos a medir la importancia que la actividad bélica tuvo para ellas.

The legal literature compiled by the military orders of Calatrava and Santiago contains relevant information to study many aspects related to their organization, among them some that explain their link with the war. This work seeks to make a comparative study of that textual corpus formed by rules, statutes, definiciones, capitular acts and establecimientos of the two main Hispanic orders, to better know the war charism that these institutions had. In addition, our analysis can also trace parallels or divergences between one and the other, besides helping us to measure the importance that the war activity had for them.

\section{Palabras Clave - Keywords}

Órdenes militares; Calatrava; Santiago; guerra; reglas; Edad Media.

Military orders; Calatrava; Santiago; war; rules; Middle Age.

\section{Cómo citar este ARTículo / Citation}

Palacios Ontalva, J. S. (2020): «La guerra en los textos normativos de las órdenes militares de Calatrava y Santiago». Gladius, 40: 113-131. https://doi.org/10.3989/gladius.2020.05

* Proyecto de investigación: Violencia religiosa en la Edad Media peninsular: guerra, discurso apologético y relato historiográfico (ss. X-XV), financiado por la Dirección General de Proyectos de Investigación y Gestión del Plan Nacional de I+D+i del Ministerio de Economía y Competitividad (Referencia: HAR2016-74968-P). Dirección: Carlos de Ayala Martínez y J. Santiago Palacios Ontalva.

** Universidad Autónoma de Madrid, santiago.palacios@uam.es / ORCID iD: http://orcid.org/0000-0002-9606-6084 


\section{INTRODUCCIÓN}

Los diferentes marcos normativos con los que se dotaron las órdenes militares hispanas y con los que crecieron institucionalmente, así como los desarrollos jurídicos posteriores que enriquecieron aquellos primitivos textos reglares y canónicos ${ }^{1}$, constituyen una inestimable fuente de información a partir de la que conocer el grado de compromiso de estas milicias en la guerra, además de aportar informaciones diversas sobre su organización para la actividad bélica ${ }^{2}$.

El trabajo que planteamos, pretende un doble objetivo. Por una parte, tratar de dibujar la propuesta de análisis de estas fuentes normativas que hemos realizado, es decir, exponer sintética y ordenadamente los aspectos relacionados con la actividad militar que se pueden detectar en aquellos textos. Deteniéndonos, después, en los detalles que aporta la normativa de las órdenes estudiadas, para intentar extraer conclusiones sobre la incidencia que esta actividad tuvo en el devenir histórico e institucional de las mismas.

\section{LAS POSIBILIDADES DE LAS FUENTES NORMATIVAS}

Las fuentes normativas de las órdenes de Calatrava y Santiago forman un amplio conjunto de textos canónicos ${ }^{3}$, donde aparecen dispersas referencias alusivas a su actividad militar, a sus formas de organización, cuadros de mando, integrantes de sus huestes, equipamiento militar, condiciones de servicio de armas, fortificaciones, etc. Para tratar de organizar esas menciones, hemos establecido una serie de categorías esenciales en las que aglutinarlas.

1. La vocación de servicio militar, los objetivos y compromisos en defensa de la cristiandad, así como las justificaciones bernardianas en torno a la actividad militar de las órdenes, expuestas en un lenguaje de tono cruzadista, son cuestiones esenciales de los textos normativos más antiguos, que van a transmitirse, copiarse y enriquecerse en sucesivas ocasiones en los preámbulos de las reglas y de las bulas papales de aprobación ${ }^{4}$.

1 En torno al desarrollo normativo y las tradiciones reglares seguidas por las diferentes órdenes: Linage Conde, 1981; Forey, 1992; Ayala, 2003: 151-164; Josserand, 2004; Demurger, 2005: 89-105; Rodríguez-Picavea, 2008: 273-300.

2 La actividad militar no ha pasado desapercibida para quienes han realizado análisis panorámicos de estos textos, véase O'Callaghan, 1996a; Ayala, 1996. Aunque no hayan sido consideradas las fuentes más parleras en este sentido (Ayala, 2007: 231).

3 Las fuentes que han proporcionado información para elaborar este trabajo, aunque no son todos los textos normativos de ambas órdenes, han sido las siguientes. En el caso de la orden de Calatrava: primera regla o forma vivendi, y su confirmación pontificia, 1164 (Ortega y Cotes et alii, 1761: 3-6); segunda forma vivendi y su confirmación, 1186 y 1187 , respectivamente (Ortega y Cotes et alii, 1761: 20-25); Establecimientos del abad Guido I de Morimond, 1195 (Lomax, 1961: 491-492); tercera forma vivendi y su confirmación, 1199 (Ortega y Cotes et alii, 1761: 30-35); Definiciones de Salvatierra, 1196-1211 (Lomax, 1961: 492-494); Definições de finales de siglo XIII, posiblemente del maestre Juan González, 12671284 (Oliveira, 2015: 127-136 y 2020: 21-26); Definiciones de 1304, 1307, 1325, 1336, 1338 y 1383 (del maestre Pedro Muñiz de Godoy) (O'Callaghan, 1975b); Definiciones de 1383 (de Juan II, abad de Morimond), 1397, 1407, 1408 y 1418 (O'Callaghan, 1996b); Definiciones de Almagro, 1433 (Archivo Histórico Nacional [AHN], Órdenes Militares [OOMM], 1348C, Registro Escrituras Orden de Calatrava, vol. VIII, fols. 66r-73v); definiciones de 1468 (O'Callaghan, 1975c). En el caso de la orden de Santiago: regla primitiva, 1167-1168 (Leclercq, 1958: 353-355); segunda regla latina inserta en la bula de confirmación de Alejandro III, 1175 (Martín, 1974, doc. 73: 248-254); $1^{a}$ Regla castellana del siglo XIII (Lomax, 1965: 221-231); Establecimientos del maestre Pelayo Pérez Correa de 1251, 1252, 1259, 1265, 1266 y 1274 (Biblioteca Nacional [BN], Manuscrito [Ms.] 8.582, fols. 56r-61v; 62r-62v; 64r-65r; 65r-66r; 62v-63v y 44v-48v, pub. Josserand, 2004, https:// books.openedition.org/cvz/3058\#bodyftn6); Establecimientos de 1310 y $1480-1481$ (BN, Ms. 8.582, fols. 49r-55v y 244r278v); Establecimientos de 1440 (Ostos Salcedo, 2008: 187-292); leyes capitulares del maestre infante don Enrique, 1440; leyes capitulares del maestre Alonso de Cárdenas, 1480-1481 (Madrid y Medina, 2005); y los Establecimientos modernos de Ruiz de Morales (1998).

4 Linage Conde, 1981: 37-39 y 41-42; O’Callaghan, 1996a: 15-17; Ayala, 1996: 61-63. 
2. También aparecen en las regulaciones de las milicias indicaciones sobre el tipo de hábito que debían vestir los freires ${ }^{5}$. O acerca del equipamiento militar básico de estos combatientes, dotados de caballo y armas, así como de otros componentes de los arreos del caballero, que se les debía proporcionar por la orden en el momento de tomar el hábito o profesar, pero que también se les podía retirar en caso de causar baja o incurrir en alguna pena tipificada. Del tratamiento que se otorga a dichos elementos de la panoplia militar se deducen, además, las connotaciones feudales del pacto suscrito entre el maestre y los freires ${ }^{6}$.

3. Las disposiciones en relación con la preminencia del maestre y su autoridad suprema, además de la obediencia debida a su persona o sobre su capacidad coercitiva, son constantes en la normativa y son rasgos que parece lógico extender a su liderazgo en el terreno militar?

4. Algunos datos en torno a la estructura de las tropas reunidas por las órdenes o sobre los distintos componentes que las integraban también se vislumbran en estas reglas, establecimientos y definiciones, siendo particularmente significativas las menciones a los séquitos armados de las diferentes dignidades ${ }^{8}$.

5. Aunque no tenemos detalladas indicaciones acerca de cómo ejecutaban las campañas o acciones militares, y mucho menos las precisiones tácticas sobre el papel de los hermanos en ellas, la normativa ofrece algunas pautas o establece ciertas condiciones bajo las que las órdenes combatieron. Hablamos de disposiciones que revelan el esfuerzo y peligrosidad de la lucha; que aluden a la necesidad de que los freires combatieran unidos y agrupados bajo sus enseñas; que establecen, asimismo, algunas precisiones en torno al botín y los prisioneros; o limitan la violencia y el derramamiento de sangre.

6. Preocupa también en la normativa la asistencia a los heridos en contienda, la de los hermanos viejos o enfermos, y acerca de la situación de los cautivos ${ }^{9}$. Respecto a los primeros, las reglas hablan de la fundación de hospitales en la frontera, del establecimiento de encomiendas hospitalarias en la retaguardia, y también se refieren a hospitales de campaña. En torno, por otro lado, a la labor redentorista de los freires calatravos o santiaguistas, no pocas disposiciones reglares se ocupan sobre el modo de contribuir a sacar de ese estado de cautiverio a los hermanos que hubieran sido hechos prisioneros.

7. En último lugar, nuestro estudio sobre las fuentes normativas de las órdenes se ha centrado en todo lo referido a la gestión, mantenimiento y control del ingente patrimonio fortificado acumulado por ellas. Y aquí nos hemos visto obligados a distinguir entre tres tipos de instrucciones legales: unas referidas a las formas de adquisición y las condiciones de entrega de los castillos integrados en los señoríos de estas instituciones; otras que afectan al mantenimiento operativo de aquellas fortalezas en lo que concierne a sus guarniciones, arquitecturas, vigilancia y dotación; $y$, por último, otra serie de normas que buscaban garantizar el control jurisdiccional de las órdenes sobre tan importante recurso militar.

\section{LA GUERRA EN LA NORMATIVA DE LAS ÓRDENES MILITARES HISPANAS}

\subsection{La orden de Calatrava}

La orden de Calatrava nació en la frontera, en uno de los lugares más expuestos y peligrosos de la misma a mediados del siglo XII, para defender la fortaleza homónima de Paganis

\footnotetext{
5 O’Callaghan, 1996a: 27-28.

6 Ayala, 1996: 67

7 O’Callaghan, 1996a: 25; Ayala, 1996: 78

8 O’Callaghan, 1996a: 19; Ayala, 1996: 68-70

9 Ayala, 1996: 73-74.
} 
inimicis Crucis Christi $^{10}$. Muchos de sus primeros integrantes eran o habían sido hombres de armas que, junto a los monjes cistercienses de Fitero, formaron una comunidad híbrida, desde el principio denominada milicia y destinada a proteger aquella vieja ciudad islámica. Muy pronto, sin embargo, el modelo «laical» de orden acabó triunfando frente al «monacal»; el maestre García sustituyó al abad Raimundo, pese a lo que el vínculo con el Císter no se rompió ${ }^{11}$. De ello es prueba que su capítulo general concediera muy pronto una primera «forma de vida» a la institución, en la quedaba clara esa vocación de servicio militar revestida además de un matiz sacralizado ${ }^{12}$. Nos referimos a un primer texto normativo confirmado por el papa Alejandro III en 1164, donde se caracterizaba a los fratres «ceñidos con armas propias de caballeros ${ }^{13}$, quienes personalizaban la transformación de una militia mundi a una militia $D e i^{14}$, tal y como Rodrigo Jiménez de Rada también certificaba poco tiempo después, al definir a los calatravos como religiosos que rezan, ciñe espada y viven una vida de rigores ${ }^{15}$.

Junto a estos elevados propósitos y argumentos justificativos, en los primeros textos reglares calatravos se encuentran también normas concretas para a regir la actividad militar de la milicia. Por ejemplo, indicaciones sobre el tipo de hábito que debían vestir los freires, que debía ser adecuado para montar a caballo y combatir, uniformizado y sin ostentaciones ${ }^{16}$. Y sabemos algo incluso sobre el equipamiento militar básico de estos combatientes, dotados de arma et equum $^{17}$ — que se les podían retirar en caso de castigo-, así como de otros elementos propios de los arreos del caballero - frenos y espuelas - y sus elementos de protección personal - pectorales-, que, sin embargo, no podían estar decorados con oro, como correspondía a los austeros guerreros de la orden ${ }^{18}$.

La obligación de que el maestre proveyera del vestuario adecuado a los freires una vez al año ${ }^{19}$, y que hiciera lo propio con el equipamiento militar de los hermanos, fueron preocupaciones comunes, y se recuerda además que eran atributos que el caballero podía perder con frecuencia en caso de hallarse culpable de diferentes delitos ${ }^{20}$. En este sentido, un interesante

10 Así se expresa el privilegio fundacional otorgado por Sancho III en 1158 (Ortega y Cotes et alii, 1981: 2).

11 Sobre las circunstancias que rodean el origen de la orden y su filiación cisterciense: O'Callaghan, 1975a; Villegas, 1991; Ayala, 2000, 2016; Josserand, 2005. Para comprender el contexto ideológico en el que surgió, tanto en clave hispana como en el contexto general de la cristiandad: Ayala, 2009a, 2009b.

12 Ortega y Cotes et alii, 1761: 3-4.

13 Militaribus armis accinti (Ortega y Cotes et alii, 1761: 5)

14 Linage Conde, 1981: 46.

15 Jiménez de Rada, 1987, Lib. VII, Cap. XXVII. En las tardías palabras de Rades, sus hombres tomaron vn habito moderado y templado de religion, como conuenia para el exercicio de la guerra, y se llamaban asimismo freyles y no frayles: por differenciarse de las otras Ordenes que nos son militares (Rades y Andrada, 1572: fols. 6v y ss., Chronica de Calatrava).

16 Tunicas ad aequitandum idoneas; pelliceas, quoque agninas, sed breves; vestes moderatas, honestas, commodas (Ortega y Cotes et alii, 1761: 4, 5, 21, 22 y 31). Los estatutos de Salvatierra se refieren a ello con las siguientes indicaciones: In habitu fratrum nulla diuersitas habeatur set mantelli et garnachie unius maniere sint; Fratres laici totum caputium super garnachiam ponant. Prohibían además el uso de capas con mangas largas, permitiendo las de mangas cortas y anchas para quienes combatían al sur del puerto de Orgaz (Lomax, 1961: 490-493).

17 Ortega y Cotes et alii, 1761: 4 y 21; Definiciones de Salvatierra, 1196-1211, n. 24 (Lomax, 1961: 494).

18 Definiciones de Salvatierra, 1196-1211, n. ${ }^{\circ} 18$ (Lomax, 1961: 493).

19 Las Definiciones calatravas de 1325 y 1336 son explícitas en este sentido: que el maestre de, en cada año, la vistiaria a los freyres, assi como en tiempo de Juan Gonzales, maestre, solia dar..., y que el maestre provea los freyres de convento de la vestidura de saya, e pellot, e escapulario, e calzas, cada año, e de dos en dos años, tavardos, et su vestidura delgada, segun suele (O’Callaghan, 1975b: 270 y 278). Sobre las mencionadas definiciones atribuidas al maestre Juan González, véase Josserand, 2009: 229-230 y, sobre todo, Oliveira, 2015: 116-117 y 2020: 12.

20 Difiniciones de 1304, n. ${ }^{\circ} 12,16,18,22,23$ y 24; Definiciones de 1325, n. ${ }^{\circ} 18$; Definiciones de 1336 , n. ${ }^{\circ} 11,20$, 22, 39 (O’Callaghan, 1975b: 265-267, 272); Definiciones de 1397, n. ${ }^{\circ} 6$ y 17 (O’Callaghan, 1996b: 113-115). Parece, en todo caso, que el hecho de perder el caballo y las armas, como pena impuesta por el maestre ante diferentes infracciones, es cada vez menos frecuente conforme avanza el siglo XIV. 
capítulo de las Definiciones de 1397 se refiere también a este equipo básico del freire caballero en el momento de su muerte, ordenando al comendador mayor que no lleve sino el cavallo i las armas de su cuerpo, no mas, lo que refuerza la idea de que estos elementos, imprescindibles para su actividad militar, pertenecían a la orden, y sus gestores podían disponer de ellos con libertad $^{21}$.

Otro aspecto en el que parecen incidir aquellos textos normativos es el referido al protagonismo, autoridad y deber de obediencia manifestado a la figura del maestre, situado por encima del prior, de monachis o de fratres - tanto laici como milites -; con poder para imponer el ayuno a los hermanos que vivieran con él en el castillo ${ }^{22}$; con capacidad coercitiva y disciplinaria en asuntos generales; y con una autoridad, que le conferían las bulas de confirmación, también sobre la construcción de iglesias u oratorios ${ }^{23}$, que parece lógico extender a la construcción y reforma de castillos, o prolongar al mando ejercido en la hueste. Sin embargo, esos poderes estaban limitados significativamente a la hora de permitir acoger en la orden a algún freire que hubiera quebrantado treguas del rey combatiendo contra christianis uel paganis, que solo podía volver a seno de la institución si el visitador y el propio monarca lo autorizaban ${ }^{24}$.

Como sabemos, el desarrollo normativo de la orden durante el XIV fue notable, contabilizándose hasta ocho elaboraciones legislativas durante la centuria. No obstante, en esos textos las evidencias que nos interesan son muy pocas en comparación con otras preocupaciones más ampliamente representadas en la regla, en claro contraste, además, con la enorme actividad bélica que desarrolló la institución entonces y su presencia en todas las movilizaciones y escenarios posibles del periodo. En todo caso, en las sucesivas definiciones siguen apareciendo disposiciones sobre la preminencia del maestre y su autoridad suprema, además de recordar la obediencia debida a su persona, o la prohibición de la rebeldía ${ }^{25}$, normas que se reiteran en un momento de especiales turbulencias en el seno de la institución ${ }^{26}$.

En relación con los integrantes de la hueste calatrava y la sociología de sus miembros, la normativa es poco elocuente, e incluso confusa. Por ejemplo, acerca de la contratación de mercenarios en fechas tempranas que, si nos fiamos del testimonio de Jiménez de Rada, parece que pudo haber realizado el propio abad Raimundo ${ }^{27}$. Sin embargo, los mercennariorum que aparecen en las Definiciones de Salvatierra, aunque hayan sido interpretados muchas veces

21 Definiciones de 1397, n. ${ }^{\circ} 18$ (O’Callaghan, 1996b: 115). A finales del siglo XIII se había dispuesto en esos casos que Armas e cauallos quedasen ao arbitrio do comendador moor. e as camas ao arbitrio do cellareyro (cillero) (Definições finales siglo XIII, n. ${ }^{\circ}$ 17, Oliveira, 2015: 131-132 y 2020: 23). Por esta y otras informaciones, parece que la responsabilidad de los comendadores mayores en lo referido a la actividad bélica era indudable.

22 Ortega y Cotes et alii, 1761: 22 ( $2^{\mathrm{a}}$ bula confirmación de Gregorio VIII) y 32 ( $3^{\mathrm{a}}$ bula confirmación de Inocencio III).

23 Ortega y Cotes et alii, 1761: 24 ( $2^{\mathrm{a}}$ bula confirmación de Gregorio VIII) y 34 ( $3^{\mathrm{a}}$ bula confirmación de Inocencio III).

24 Definiciones de Salvatierra, 1196-1211, n. 32 (Lomax, 1961: 494).

25 Las Difiniciones de 1304 mandaban a todos los freyres que no sean [rebeldes en el] capitulo a recebir la disciplina de la orden; establecía que si algunos freiles se alçaren con moros, o con christianos, contra la orden, que fagan la penitencia de conspiradores, e que sean encarcelados [gravemente] que nunca salgan ende; recordando a todos los freyres que fagan reverencia e honrra a su maestre, e a sus prelados, como es derecho. E non vayan contra el maestre a mala rebeldía, [ni con armas, ni contra el comendador maior, ni contra] el clavero (n. ${ }^{\circ}$ 4, 10 y 11, O'Callaghan, 1975b: 263-264). Según las Difiniciones de 1325, los conspiradores solo podían ser absueltos por los visitadores y si algun Freyre se alzare con castiello, o con casa de la orden, contra su maestre, que sea encarcelado por dos años, e non sea perdonado (n. ${ }^{\circ} 14$ y 16, O’Callaghan, 1975b: 271-272). En parecidos términos se manifiestan las 'Difiniciones' de 1336 (n. ${ }^{\circ} 3,8,9$ y 38, O'Callaghan, 1975b: 274-279).

26 Reiteramos aquí nuestra duda, al menos para el ámbito peninsular, acerca de la observancia de una disciplina férrea en el terreno militar que surgía del voto de obediencia monástica emitido por los freires, y convertía las milicias de las órdenes en las tropas más eficaces de cuantas podían comparecer en un campo de batalla en la Edad Media. Un ejemplo de las implicaciones militares que tuvo una de las numerosas crisis y cismas que azotaron a las órdenes, puede verse en Ayala, 1999

27 Jiménez de Rada, 1987, Lib. VII, Cap. XIV. 
como combatientes asalariados, C. de Ayala recuerda que seguramente serían campesinos remunerados con mercede por su trabajo agrícola ${ }^{28}$.

En el caso de las condiciones de acceso a la milicia y el origen noble de los freires que asumieran el oficio de las armas, hablamos de aspectos especialmente regulados en el siglo $\mathrm{XV}$, aunque esas realidades ya habían aparecido en textos normativos anteriores ${ }^{29}$, cuando la institución comienza un evidente proceso de señorialización ${ }^{30}$. Se estableció entonces que los aspirantes a ingresar en la orden debían ser hijos de legitimo matrimonio ${ }^{31} \mathrm{y}$, en el caso concreto de aquellos que fueran a adquirir el status militarium, debían acreditar orígenes nobiliarios o hidalgos ad modum Hispanie ${ }^{32}$. Pero además se estableció un periodo obligatorio de un año en el convento ad adiscendam regulam et ad vivendum et sciendum ordinis ceremonias et asperitates, para omnis miles que quisieran recibir el hábito de la orden. Estos novicios, además, no podían ser menores de diez años ni recibir encomiendas con menos de diecisiete; hasta el momento en que la tuvieran, el maestre estaba obligado — de las rentas de la mesa maestral-, a proveer a los freires de todo lo necesario en vestido y alimentación — seguramente también en relación con su equipo militar, como veíamos con anterioridad-; asumiendo después estos comendadores el compromiso de habitar en las domus et castra que integraban el patrimonio de la orden, para evitar así que dichos inmuebles acabaran arruinándose ${ }^{33}$.

La normativa también se ocupa de revelar ciertos aspectos relacionados con el desarrollo de la actividad bélica, aunque estos apenas sean tangenciales aproximaciones a la ejecución o los preparativos de las campañas, o ilustren las duras condiciones de vida en la frontera. Nos referimos, por ejemplo, a las exenciones sobre los ayunos que afectaban al maestre y a sus subordinados más comprometidos en la guerra ${ }^{34}$, o a la libertad que tenía aquel para pasar por alto ese precepto, siempre y cuando estuviera en el campo ${ }^{35}$, lo que significa la toma de conciencia de la dureza de esa actividad y el alivio de ciertos sacrificios que podían comprometer el éxito o efectividad de las tropas.

En un par de ocasiones - durante el siglo XIV, concretamente-, encontramos normas que obligaba a los freires y al maestre a inventariar los bienes de la orden cuando iban a la frontera, al igual que en caso de peligro de muerte, con el propósito declarado de salvaguardar el patrimonio de la institución ante la posibilidad de que los responsables de su mantenimiento pudieran morir o ser hechos cautivos ${ }^{36}$. E igualmente podemos mencionar la preocupación que reflejan algunas definiciones calatravas por la dotación de ciertas enfermerías, labor que correspondía al clavero. Nos referimos concretamente a las asociadas a la propia encomienda

28 Definiciones de Salvatierra, 1196-1211, n. ${ }^{\circ} 23$ (Lomax, 1961: 493). Véase Ayala, 2007: 240

29 Forey, 1986.

30 Rodríguez-Picavea, 2007.

31 Las Difiniciones de 1325 anticipaban: que el maestre non nombre a ninguno que non sea legitimo o fixo de dueña, de cavallero, o de escudero, que cavallero pueda ser (O'Callaghan, 1975b: 270). En las Definiciones de 1468 el precepto tomó esta otra forma: statuimus et mandamus quod nullus ignobilis vel non generosus fidalgus ad modum Hispanie amodo asumatur ad dictum ordinem militie sub pena excomunicationis (n. ${ }^{\circ} 62$, O'Callaghan, 1975c: 263-264).

32 Definiciones de 1418, n. 5 y 62 (O'Callaghan, 1996b: 120-121).

33 Definiciones de 1468, n. ${ }^{\circ} 22,23,27$ y 36 (O’Callaghan, 1975c: 248-249 y 253).

34 La segunda forma vivendi dada en 1186 establecía una serie de ayunos para los hermanos qui in domi sunt, mientras que el maestre podía aliviar dicha carga a aquellos que estaban inter saracenos (Ortega y Cotes et alii, 1761: 21). La bula de confirmación dada por Gregorio VIII un año después dispone lo mismo para quienes in castris militiae fuerint (Ortega y Cotes et alii, 1761: 22).

35 Definiciones de 1325, n. ${ }^{\circ} 1$ (O’Callaghan, 1975b: 269).

36 ...mandamos que el maestre e todos los freyres, por que los bienes de la orden sean guardados, e el peligro de las animas, asi mismo que quando fueren en habito mortis, o en frontera, que fagan enventario de los bienes que tobieren de la orden (Definiciones de 1336, n. ${ }^{\circ} 33$, O'Callaghan, 1975b: 278; Definiciones de 1397, n. ${ }^{\circ} 17$, pub. O'Callaghan, 1996b: 114-115). 
de la clavería, a la de Alcañiz, Zorita y Martos, en las que los hermanos se recuperarían de sus dolencias y, suponemos también, de las heridas producidas en acciones militares ${ }^{37}$.

En las definiciones calatravas del siglo XV se detecta también la preocupación por mantener la unidad de acción de la orden, lo cual implicaba que los freires calatravos de las encomiendas aragonesas no presuman de ir ni se poner debaxo de la vandera de algun señor temporal (...) por defension de la iglesia, del mismo reyno o de la republica o de otra manera, sino todos los dichos cavalleros, freiles, vaian debaxo la vandera de la Orden juntamente si estuviere presente, guardando contino la unidad de la Orden ${ }^{38}$. Y esa misma idea de unidad e identificación homogénea de los miembros de la milicia está presente en los capítulos referidos a la vestimenta de los hermanos, que se regula de manera precisa en corte, tamaño y color, como hemos visto, de forma que todos los freires lleven mantellis, tunicis y las cruces rojas identificativas de la institución, tam in curiis regum et dominorum quam etiam in guerris, lo que casi parece un intento de uniformizarlos ${ }^{39}$.

No menos interesante sobre el modo de proceder de la orden en la guerra es otra definición de 1468 dedicada a la redención de cautivos propios, que nos proporciona evidencias tangibles de la actividad guerrera de la institución y sus posibles consecuencias, así como acerca de la responsabilidad que tenían los maestres, los preceptores y otros milites en esta labor redentora ${ }^{40}$.

Otro asunto prioritario de las definiciones tiene que ver con la gestión, el mantenimiento y operatividad de sus fortalezas, así como con el control jurisdiccional de las mismas. En 1325, por ejemplo, ordenaban dar las retenencias para su mantenimiento de forma regular, por que no venga daño a los castiellos, y a disponer todo lo necesario para realizar visitas periódicas a estos lugares estratégicos, para saber como estan de armas e de mantenencias, por que [por] codicia de los freyres, los logares non se pierdan ${ }^{41}$.

Y preocupa también el homenaje debido por estas fortificaciones, que debían prestar los freires que las tuvieran al maestre ${ }^{42}$; la imposición de severas penas para quienes se rebelaran desde una fortaleza contra él ${ }^{43}$; la obligatoria hospitalidad debida al maestre en ellas ${ }^{44}$; o la

37 Difiniciones de 1304, n. ${ }^{\circ}$; Definiciones de 1325, n. 13 (O’Callaghan, 1975b: 263-264, 271).

38 Definiciones de 1407, n. $^{\circ} 4$ (O’Callaghan, 1996b: 117). Aunque no sea objeto de nuestro interés en estas páginas, las cartas de hermandad entre las diferentes órdenes contemplaron prioritariamente esta necesaria unidad de acción de los freires de las distintas milicias. Véase O'Callaghan, 1969; Ruiz Gómez, 2000: 420-422; Ayala, 2003: 413, 421-422, 429430 y 434; Josserand, 2004: 270.

39 Definiciones de 1433 (AHN, OOMM, 1348C, Registro Escrituras Orden de Calatrava, vol. VIII, fols. 68v-69r); Definiciones de 1468, n. $^{\circ} 6$ (O'Callaghan, 1975c: 242).

40 Definiciones de 1468, n. 38 (O'Callaghan, 1975c: 253).

41 Difiniciones de 1325, n. ${ }^{\circ} 10$ y 27 (O’Callaghan, 1975b: 271 y 273). Algunas referencias bibliográficas acerca del asunto de las retenencias: Ayala, 2001: 556-558, 2003: 575-590 y 2006. La preocupación por el mantenimiento de los castillos de la orden pudo surgir entonces debido a las acusaciones lanzadas contra el maestre, García López de Padilla. Durante su turbulento maestrazgo se perdieron algunas fortalezas fronterizas como Alcaudete, Locubín, Susaña, Chist y Mathet, según las denuncias de negligencia presentadas ante el monarca, por non les dar retenencia et bastecimiento (Crónica de Alfonso XI, p. 200; Gran Crónica de Alfonso XI, I, p. 382). La oposición al maestre la encabezó el clavero, Juan Núñez, y sus intenciones de hacerse con el maestrazgo provocaron un cisma en la institución y una auténtica guerra civil en su seno (Rades y Andrada, 1572: fols. 50r-52r y 54v, Chronica de Calatrava).

42 Definições finales siglo XIII, n. ${ }^{\circ} 2$ (Oliveira, 2015: 128-129). La costumbre parece que se remonta a las exigencias hechas por Alfonso X al maestre de Calatrava, en 1260. Los responsables de las órdenes, a su vez, trasladarían a sus freires el deber del homenaje por los castillos que poseyeran, que, a través del eslabón maestral, se ponían al servicio del rey (Ayala: 2001: 552-554, 2003: 567-573; Josserand, 2004: 392). Las Difiniciones de 1325, sin embargo, no solicitaban una explícita declaración de homenaje, y ordenaban que el maestre non tome omenaxe a ningun Freyre por castiello, siendo la profesión suficiente garantía de control maestral de las fortalezas y casas de la orden (n. ${ }^{\circ} 11$, O'Callaghan, 1975b: 271).

43 Difiniciones de 1325, n. ${ }^{\circ} 16$ (O'Callaghan, 1975b: 272). Años antes, en 1318, los maestres de Calatrava, Santiago y Alcántara habían acordado un procedimiento de ayuda mutua en caso de que algún freire se rebelara contra su maestre desde algún castillo (AHN, OOMM, Registro de Escrituras de la Orden de Calatrava, V (1345 C), fol. 155v).

44 Difiniciones de 1325, n. ${ }^{\circ} 11$ (O’Callaghan, 1975b: 271). 
preocupación general por el mantenimiento de los inmuebles que formaban parte de su patrimonio, reflejado en la institución de las mencionadas visitas periódicas por parte de duos fratres, militem et clericum de ordine discretos et providos ${ }^{45}$, que debían supervisar el estado de conservación de las fortalezas calatravas ${ }^{46}$. Dichas visitas continuaron de forma regular ${ }^{47}$, aunque en 1468 se estableció que el intervalo entre una y otra fuera bianual ${ }^{48}$. Aquel año, además, se proponía expresamente que los visitadores recorrieran singula castra, villas, muros, turres, pontes, domus, ceteraque loca comendarum et eclesiarum ${ }^{49}$, lo que pone de manifiesto una mantenida preocupación por el estado de los elementos de arquitectura defensiva con los que contaba la milicia, incluso en fechas tardías o escenarios alejados de la frontera.

En este sentido, se entendería también la preocupación de las Definiciones de 1397 en relación con las atribuciones del subcomendador del convento de Calatrava, que debía ser un freile cavallero obligado a hacer homenage por el alcaçar al maestre, así como a controlar las salidas y entradas de caballeros y otros servidores en dicha fortaleza, de modo que la sede maestral siempre estuviera fielmente sujeta a su autoridad y bien defendida ${ }^{50}$.

Los castillos se revelan en esta coyuntura como una herramienta de poder que no podía ser usurpada en alguna de las frecuentes rebeliones internas y cismas que sufrió la institución, ni era conveniente que cayesen en manos de los distintos monarcas, progresivamente empeñados en rebajar la autoridad de los maestres y la independencia de las órdenes, entre otros medios a través del control de estos activos patrimoniales.

\subsection{LA ORDEN DE SANTIAGO}

Conocemos varias versiones de la regla de la orden de Santiago desde su fundación ${ }^{51}$, y la primera de ellas, en palabras de Eloy Benito Ruano, no contenía sino unos pocos preceptos morales, religiosos y rituales para guiar a los caballeros en su vida comunitaria, aunque la siguiente fórmula: Tota sit omnium intentio Ecclesiam Dei defendere, sarracenos inpugnare, remarcaría una inequívoca vocación militar de la institución desde sus inicios, pese a la ausencia de prescripciones expresas para regular dicha actividad castrense ${ }^{52}$.

Inserta en la bula de confirmación de Alejandro III de 1175 se contiene una versión de la regla primitiva que está introducida, a su vez, por un interesante relato consagrado al tema de la conversión de los equites diaboli en servidores de Jesucristo, hombres de noble linaje dispuestos a abandonar su anterior vida de pecado para ofrecerla, hasta el martirio si hiciera falta, al servicio de Dios $^{53}$. Y de otra versión latina perdida pero fechable en la primera mitad del siglo

45 Definiciones de 1383, n. ${ }^{\circ} 8$ (O’Callaghan, 1996b: 107). En relación a las visitas, véase: Forey, 1992: 166-168 y 2015: 95-122; Ayala, 2003: 289-293.

46 Otras disposiciones en relación con las visitas calatravas: Definiciones de 1383, n. ${ }^{\circ} 2$ (O’Callaghan, 1975a: 283).

47 Definiciones de 1407, n. ${ }^{\circ} 3$; Definiciones de 1418, n. ${ }^{\circ} 6$ (O’Callaghan, 1996b: 116 y 121).

48 Desde finales del siglo XIII, las visitas del abad de Morimond a Calatrava se habían espaciado cada tres años (Definições finales siglo XIII n. ${ }^{\circ}$ 6, Oliveira, 2015: 130 y 2020: 23).

49 Definiciones de 1468, n. ${ }^{\circ} 13$ y 31 (O’Callaghan, 1975c: 245 y 250).

50 Definiciones de 1397, n. ${ }^{\circ} 12$ (O'Callaghan, 1996b: 114).

51 Leclercq, 1958; Ferrari, 1960; Lomax, 1965: 51-53; Gallego Blanco, 1971; Benito Ruano, 1978: 175-178; Sastre Santos, 1982.

52 Benito Ruano, 1978: 176; Leclercq, 1958: 354; Aguado de Cordova et alii, 1719: 1-3. Linage insiste en su inequívoca destinación castrense, pero sobre todo en los muchos elementos monásticos contenidos en la primitiva regla (Linage, 1981: 50-51).

53 Martín, 1974, doc. 73: 248-254; Aguado de Cordova et alii, 1719: 1-2 y 13-17; Rades y Andrada, 1572: fols. 12v-15v, Chronica Santiago. Esta segunda regla latina, además, aporta información sobre disposiciones orgánicas y funcionales de carácter institucional en relación con los cargos de la institución y sus atribuciones, derechos y obligaciones (Benito Ruano, 1978: 177).

Gladius, XL (2020), pp. 113-131. ISSN: 0436-029X; eISSN: 1988-4168. https://doi.org/10.3989/gladius.2020.05 
XIII, conocemos la primera traducción castellana en fecha coetánea, con 92 disposiciones $^{54}$ que puede considerarse, con las pequeñas variantes de los respectivos manuscritos, como 'definitiva' $y$ ha sido reiteradamente objeto de impresión en los siglos modernos ${ }^{55}$.

Lomax tomó estos textos iniciales en su conjunto como descripciones de la vida de la Orden hacia mediados del siglo XIII ${ }^{56}$, pero lo cierto es que su contenido esencial se centra en un código disciplinario y penal para la resolución de posibles conflictos en su seno, siendo muy deficitario en otras disposiciones de índole administrativa, orgánica o bélica, igualmente necesarias para el funcionamiento cotidiano de la orden ${ }^{57}$. Para cubrir esas otras necesidades fueron promulgados a lo largo del tiempo los llamados establecimientos, es decir, disposiciones emanadas de los acuerdos tomados en el Capítulo General que debía reunirse cada año por Todos los Santos. Con ellos se llegó a formar un corpus legislativo complementario a la regla capaz de ayudar al buen gobierno de la institución; una doctrina que revela numerosos detalles en torno a la vocación y desempeño bélico de los hermanos de la orden, que conviene analizar ${ }^{58}$.

En primer lugar, correspondía al maestre proporcionar a los hermanos sus vestidos y el equipo militar básico. Los textos normativos buscaron estandarizar aquellos en colores, formas y tipos de prendas permitidos desde muy pronto $^{59}, \mathrm{y}$, aunque con el tiempo se debieron relajar las austeras costumbres iniciales, los hermanos al menos debían llevar las señales de la institución sobre las vestiduras. Además, conocían las características que debían presentar sus hábitos, aunque se permitían determinadas licencias en su corte para quienes usan la guerra de los moros; siendo obligatorio, sin embargo, que los caballeros llevaran siempre consigo sus mantos blancos para las reuniones capitulares, para comulgar o para servirles de mortaja ${ }^{60}$.

Acerca de la panoplia de estos combatientes, los textos hablan genéricamente de caballo y armas — a veces solo en el articulado de las penas posibles por determinados $\operatorname{castigos}^{61}$-, pero también se mencionan lorigas, así como otros elementos esenciales de su arnés o del que portaban sus monturas - incluso la provisión de herraduras para las caballerías que participasen en hueste, ó en recoa ${ }^{62}$ - A este respecto la normativa nos informa también acerca del origen de alguno de esos recursos, que bien procedían del botín de las cabalgadas, como dicen

54 Lomax, 1965, doc. 1: 221-231 (en adelante $1^{a}$ Regla castellana)

55 Benito Ruano, 1978: 178. Véanse, por ejemplo: Medrano, 1627; Ruiz de Morales, 1998. También la segunda parte de la [Primera] Historia de la Orden de Santiago contiene un resumen de la Regla (Orozco y Parra, 1978: 334-352).

56 Lomax, 1965: 53.

57 Benito Ruano, 1978: 178.

58 Lomax, 1965: 53-54 y 65; Benito Ruano, 178: 179-184; Josserand, 2004.

59 Vestes albi, pardi et nigri coloris, et pelles habeant, et omnia supradicta secundum magistri pruidentiam conservent (Leclercq, 1958: 355). La traducción romance exacta en la $1^{a}$ Regla castellana, n. ${ }^{\circ} 33$ (Lomax, 1965, doc. 1: 225 ).

60 La $1^{a}$ Regla castellana, n. ${ }^{\circ} 54$ y 64 (Lomax, 1965, doc. 1: 228-229), establece como castigo de determinadas infracciones la retirada de la sennal de la uestidura. Los Establecimientos de 1251 y 1265 se encargaron de definir las características de estos vestidos en sus artículos 44 y 45, y 6, respectivamente; los de 1259 (art. 1) recuerdan la obligatoriedad de que los freires estuvieran identificados con los símbolos de la institución (BN, Ms. 8.582, fols. 60r-60v; 64r; $65 \mathrm{v}$ ); mientras en los Establecimientos de 1310 (arts. 2, 27 y 28) aparte de confirmarse el deber de los maestres de vestir a sus hermanos, se establece la uniformidad de los séquitos que debían acompañarles a ellos, a los comendadores mayores, a los priores y a los comendadores de tierra llana (Aguado de Cordova et alii, 1719: 261 y 263). Los Establecimientos de 1440 (cap. V y LXII) insisten por su parte en ciertas indicaciones previas y en la obligación de portar las señales de la orden en la guerra (Ostos, 2008: 247 y 280); y los de 1480-1481 (tit. XII) añaden un interesante dato sobre la diferencia de hábito de freires y sergentes (BN, Ms. 8.582, fol. 255r). Por último, la [Primera] Historia de la Orden (caps. XV, XVI y XX) también se ocupó de este tipo de cuestiones (Orozco y Parra, 1978: 348-349, 352).

${ }_{61} 1^{a}$ Regla castellana, n. ${ }^{\circ}$ 54, 55 y 64 (Lomax, 1965, doc. 1: 228-229); Establecimientos de 1275, art. 11 (BN, Ms. 8.582 , fol. $67 \mathrm{v})$.

62 En los Establecimientos de 1310 el maestre se comprometía a aportar un ferrero que fierre las bestias, además de frenos, è albardas è zapatos, è bragas è cebada para las bestias è de comer para los Omes (Aguado de Cordova et alii, 1719, art. 5: 261). 
los Establecimientos de 1251, o se pagaban con la mitad de los ingresos por montazgo, como se prescribe en los de 1266, que se destinaron concretamente a la compra de lorigas ${ }^{63}$.

Todos estos elementos formaban parte del pacto feudal suscrito entre los freires y la orden o sus responsables jerárquicos, se consideraban necesarios para el cumplimiento de sus funciones esenciales y era obligación de los maestres proporcionarlos ${ }^{64}$. Solo en circunstancias bélicas excepcionales estos acuerdos se podían revertir o alterar ${ }^{65}$; y, a su vez, los freires se comprometían a mantener sus cauallos e armas prestos y a no venderlos a seglares o personas de otra religión ${ }^{66}$. Tras el fallecimiento de los hermanos, caballos, armas y otros bienes debían reintegrarse a la institución, para dotar con ellos a nuevos miembros ${ }^{67}, 0$, como recoge la primera regla, para ser reaprovechados por la milicia en alguna de sus instalaciones ${ }^{68}$.

Los compromisos bélicos involucraron también a los comendadores, que contrajeron la obligación de equipar un número determinado de lanzas con las que servir a la orden ${ }^{69}$, en función del peso económico de sus respectivas encomiendas ${ }^{70}$; al igual que las villas y ciudades de su jurisdicción se comprometían a que sus vecinos, en relación con la riqueza o cuantía que alcanzaran sus haciendas, participaran proporcionalmente en la hueste de la milicia manteniendo caballo y armas de un determinado tipo y valor, y que dichos combatientes se agruparan en cuadrillas que debían ejercitarse y pasaran revista dos veces al año en sendos alardes ${ }^{71}$.

63 BN, Ms. 8.582, n. 32 y 5-7, fols. 58v-59r y 63r-63v, respectivamente. Para los baylios o comendadores mayores de la orden, el texto aclara que debía ser loriga de cuerpo e de cauallo e brafoneras.

64 En los Establecimientos de León de 1251 y en los de Mérida de 1274 queda clara esa obligación: que el maestre de a los freyles del convento cavallo e armas quando menester las ovieren para serviçio de Dios e de su Orden, e todas las otras cosas que menester fueren para esto. E que les de otrosi cada año para su vestuario a cada uno veynte e quatro varas de valençina o valençin o de arris... (BN, Ms. 8.582, n. ${ }^{\circ} 44$ y 24, fols. $60 \mathrm{r}-60 \mathrm{v}$ y $47 \mathrm{v}$ respectivamente). Se recuerda el mandato en 1310, sobre todo en caso de cabalgadas (Aguado de Cordova et alii, 1719, arts. 3 y 5: 261).

65 Establecimientos de 1275, n. ${ }^{\circ}$ 4: [O] trosi el maestre que non sea poderoso de tomar al freyre cauallo nin mula nin armas sino para el rrey o para su cuerpo quando fuere en guerra e despues que saliere de la guerra que lo den a freyre o por mengua de pan o por yeguas (BN, Ms. 8.582, fol. 67r). Prácticamente igual en Establecimientos de 1274, n. ${ }^{\circ} 8$ (BN, Ms. 8.582, fol. 46r).

66 Establecimientos de 1440, cap. XLIII (Ostos, 2008: 268).

67 ...i al tiempo de su finamientos, son obligados los dichos comendadores de encomiendas a dexar la meytad de los bienes muebles que tovieren (...) E la cama, al ospital de su provincia, e la mula, i la taça, al maestre, i el cavallo, $i$ el arnés al comendador mayor de la provinçia donde fuere. E los tales caballos, i armas no deven ser dados por los comendadores mayores a personas legas, ante son obligados de lo dar a cavalleros del abito, para que sirvan con ellos a Dios, $i$ a su orden, segund que antiguamente lo acostumbraron fazer en la dicha orden los buenos Comendadores mayores (Orozco y Parra, 1978, cap. XVII: 349). El capítulo XXIII de los Establecimientos de 1440 está dedicado a Commo los comendadores mayores han de aver las armas e cauallos de los freyres que mueren e a quién las pueden dar (Ostos, 2008: 257); y la Regla, en sus ediciones modernas, reitera la idea (Ruiz de Morales, 1998, tit. 6, cap. 30: 343).

68 Defunctorum fratrum uestes et lectisternia reseruentur obtime et per duo hospitalia domus, quorum unum est in forntera (sic), alterum in strata beati Jacobi (...) diuidantur (Leclercq, 1958: 353)

69 ... que todos los comendadores y caualleros della, en todo tiempo, tengan cauallos y armas de sus personas, y las lanças que son obligados a tener, según la obligación y institución antigua, porque (..) nos puedan seruir con ellas, según son obligados; y que las dichas lanças sean hombres de armas, encubertados y bien adereçados de cauallos y arneses, buenos y limpios, y cubiertas, pues que los fundadores desta Santa Orden y cauallería, en cauallos de la brida y a la guisa, que no como ginetes, hizieron señalados hechos, y ganaron grandes honrras, en acrecentamiento de nuestra santa fe católica (Ruiz de Morales, 1998, tit. 11: 359). También en los Establecimientos de 1480-1481, tit. XVIII (BN, Ms. 8.582, fols. $257 \mathrm{v}-258 \mathrm{r}$ ).

70 Sobre el concepto de 'lanza' en relación con las órdenes: Palacios Ontalva, 2018.

71 Leyes capitulares de 1440 (XV) y leyes capitulares de 1480-1481 (Título XLVIIIº) (Madrid y Medina, 2005: 180182 y 239-240; Ostos, 2008: 330-331). En 1440 la cuantía que obligaba a mantener un caballo de 1.500 mrs. y armas a la gineta, era de 20.000 mrs., una cifra que se elevó a 30.000 en 1480. Los vecinos que tuviesen 10.000 mrs. estaban obligados a tener ballestas de polea; ballestas de pie los de $5.000 \mathrm{mrs}$. de cuantía; los de $3.000 \mathrm{mrs}$., simplemente escudos; y quienes estuvieran por debajo de esa cantidad, al menos lanzas y dardos (Palacios Ontalva, 2018: 312-314). 
La normativa de la orden de Santiago, desde la regla primitiva ${ }^{72}$, también alude al protagonismo, liderazgo y deber de obediencia que los hermanos debían mostrar a las figuras del maestre y el comendador mayor, cuyas decisiones, entendemos también en el terreno militar, el resto de freires debían acatar sin nengun entredicho, aunque pudieran dar conseio aquello que uieren por bien $^{73}$.

Pero cuando la regla y los establecimientos se refieren a los integrantes de las huestes santiaguistas también se vislumbran otros datos, en relación con el resto de la estructura de las tropas reunidas por la orden, sobre sus distintos componentes (escuderos, sergents, criados) y los rasgos que les diferenciaban ${ }^{74}$, siendo particularmente interesantes las menciones a los séquitos armados que acompañarían a las diferentes dignidades. En 1251, por ejemplo, los Establecimientos se ocupan de los acompañantes de comendadores o baylos, cuyo pequeño contingente estaría formado por dos escuderos e dos azemilas con sus omnes, también llamados rrapazes $^{75}$. Sin embargo, el texto más completo en este sentido es el de 1274, donde se registra que en tiempo que la orden non oviere guerra con los moros nin el rrey llamare a su servicio, el maestre tendría un séquito integrado por diez freyres escuderos de cauallo e treynta onbres de pie e los ofiçiales que menester ovieren de poner de pie e de cauallo, lo que invita a pensar que el contingente sería mayor en caso de conflicto o de llamamiento real. Los priores debían acompañarse de tres freyres clerigos e tres escuderos de cauallo e dos omnes de pie e de ofiçiales commo dicho es. A los comendadores mayores les correspondía, por su parte, un acompañamiento formado por vn capellan e quatro freyres de convent $[o]$ e seys escuderos de cauallo e quinze omnes de pie e de ofiçiales commo dicho es. Mientras que para cada comendador se establecía una comitiva formada por un freyle morador e dos ommes de caballo $e$ çinco ommes de pie pero que en el tienpo de la guerra cada vno ha de yr lo mejor aconpañado que pudiere ${ }^{76}$.

La normativa santiaguista evidencia, asimismo, una realidad social jerarquizada en el seno de la institución que tendría incidencia en el terreno militar, por cuanto las misiones, armamento, especialización funcional y acceso a la gestión del patrimonio fortificado, eran diferentes para los frieres en función de su origen y estatus. Pese a que el voto de pobreza emitido en su ingreso, así como ciertas disposiciones reglares tempranas, teóricamente nivelaban a los her$\operatorname{manos}^{77}$, desde la segunda mitad del siglo XIII se percibe un proceso de señorialización que limitó el acceso a la orden a los hijosdalgo que pudieran demostrar, además, su condición de caballeros, siendo ellos los únicos que podrían tener castillo y a los que se reservaba ciertos privilegios frente a los que no tenían tal condición ${ }^{78}$.

72 Obedientes sint magistro et commendatori suo in omnibus et per omnia pro Deo et scundum Deum (...) Nullo modo audeant murmurare inter se uel contra magistrum uel contra commendatorem suum (Leclercq, 1958: 354).

$731^{a}$ Regla castellana, n. ${ }^{\circ} 75$ (Lomax, 1965, doc. 1: 230). En ese mismo texto también se recoge la censura de la murmuración en el artículo n. ${ }^{\circ} 24$ (Lomax, 1965, doc. 1: 225).

74 Los sergents santiaguistas, son llamados escuderos o escuderos de cavallo, en los Establecimientos de 1251 y 1274. En los textos tardíos se menciona ya la figura de los sergents, aunque no aportan información relevante sobre sus capacidades o actividad militar. Véase Establecimientos de 1480-1481, tit. XII (BN, Ms. 8.582, fols. 255r-255v) y Ruiz de Morales, 1998, tit. 18, cap. 1: 416. También Ayala, 1996: 69-70 y 1998.

75 Establecimientos de 1251 , n. $^{\circ} 17$ y 25 (BN, Ms. 8.582, fols. 57r, 57v y 58r).

76 Establecimientos de 1274, n. ${ }^{\circ} 18-21$ (BN, Ms. 8.582, fols. 47r-47v); Establecimientos de 1310 , art. 28 (Aguado de Cordova et alii, 1719: 263). Es plausible considerar, como ya apuntara Carlos de Ayala, este acompañamiento de los comendadores como las unidades precedentes de las futuras lanzas, en caso de que estas tuvieran una composición regular formada por ciertos combatientes, y no fueran una mera unidad de recuento fiscal, tal y como se caracterizan desde muy temprano (Palacios, 2018: 310-311).

$771^{a}$ Regla castellana, n. ${ }^{\circ} 71$ y 72 (Lomax, 1965, doc. 1: 230).

78 Establecimientos de 1259, n. ${ }^{\circ} 2,3,8$ y 9 (BN, Ms. 8.582, fols. 64r-64v); Establecimientos de 1274, n. $^{\circ} 3,4$ y 7 (BN, Ms. 8.582, fol. 45v); Establecimientos de 1275, n. ${ }^{\circ} 11$ (BN, Ms. 8.582, fol. 67v); Establecimientos de 1440 , caps. XXXV y XLIII (Ostos, 2008: 264 y 268); Ruiz de Morales, 1998, tit. 10, cap. 5: 357-358. 
Ya hemos dicho que a través de la normativa no siempre es posible reconstruir el conjunto de la actividad bélica de las órdenes y mucho menos acceder a informaciones sobre sus tácticas, entrenamiento o especialización militar, lo cual es chocante a la vista de su vocación y presencia en numerosos teatros de operaciones desde su fundación. Sin embargo, sí nos permite conocer algunos detalles concretos acerca de la preparación o desarrollo de las campañas promovidas por los freires. Por ejemplo, la recomendación recogida en la primera regla castellana para que en cabalgadas y recuas participaran solo los hermanos que no fueran miedosos, invitando a estos a realizar algunas cosas otras de la meson, que non sea embalde ${ }^{79}$.

Como vimos en el caso de la orden de Calatrava, también los santiaguistas arbitraron medidas de protección del patrimonio y familia de los miembros de la milicia que fueren sobre moros $^{80}$, y observaron que los hermanos apostados en la frontera debían comulgar semanalmente, una medida extraordinaria que subrayaba su permanente exposición al peligro de sufrir violencias o morir, que acechaba en aquel contexto ${ }^{81}$. Una vez en hueste, junto a escuetas indicaciones sobre las condiciones de manutención del comendador mayor y el de Uclés ${ }^{82}$, lo que encontramos son recomendaciones acerca de la debida unidad de acción de las órdenes bajo su pendón, así como expresas alusiones al formato y uso de la enseña de la institución ${ }^{83}$ $\mathrm{y}$, sobre todo, otras disposiciones acerca de la licencia para tomar cautivos ${ }^{84}$, o en relación con el destino de parte del botín ganado en tierra de moros $^{85}$.

La regla y los establecimientos son también elocuentes acerca del rudimentario cuerpo de sanidad militar que organizó la orden de Santiago, para asistir a los heridos y enfermos durante sus campañas. Desde el primero de estos textos se atiende la dotación, con las ropas y las camas de los hermanos fallecidos, de duo hospitalia domus, quorum unum est in forntera $(\mathrm{sic})^{86}$. La preocupación por equipar convenientemente las enfermerías de la orden, así como el intento de proteger sus recursos, rentas y gestión, continuó en el tiempo ${ }^{87}$. Pero lo que queremos destacar en este sentido es que estas enfermerías y hospitales ${ }^{88}$, convertidos en encomiendas que se establecieron no en la misma frontera pero sí en posiciones de retaguardia muy

$79 \quad 1^{a}$ Regla castellana, n. ${ }^{\circ} 15$ (Lomax, 1965, doc. 1: 224).

$80 \quad 1^{a}$ Regla castellana, $\mathrm{n}^{\circ} 18$ (Lomax, 1965, doc. 1: 224)

$81 \quad 1^{a}$ Regla castellana,.$^{\circ} 36$ (Lomax, 1965, doc. 1: 226); Ruiz de Morales, 1998, cap. 27: 178.

82 Establecimientos de 1310, art. 19 (Aguado de Cordova et alii, 1719: 262-263).

83 La seña de Santiago no podía ser llevada por ningún comendador sino en hueste del rrey e el maestre lieuela do el touiere por bien, dicen los Establecimientos de 1251, n. ${ }^{\circ} 28$ (BN, Ms. 8.582, fol. 58v). En parecidos términos también se pronuncian los Establecimientos de 1440, cap. XX (Ostos, 2008: 255-256), así como los recopilados en el siglo XVI, que vuelven a recordar el formato de los estandartes. Los de los comendadores mayores debían ser blancos, y la cruz colorada con veneras blancas, mientras el de los maestres debía ser colorado y la cruz blanca, y las veneras coloradas, perfiladas con oro, como esso mismo, el nuestro pendón puñal (Ruiz de Morales, 1998, tit. 10, cap. 8: 359). Precisamente el título XXIII de la Segunda Partida, dedicada a la guerra, autorizaba en sus leyes XIII y XIV a conventos de las órdenes de caballería y a maestres, a portar señas mayores y pendones.

84 Establecimientos de 1251, n. ${ }^{\circ} 35$ (BN, Ms. 8.582, fol., 59r); Establecimientos de 1310, art. 21 (Aguado de Cordova et alii, 1719: 263).

85 La $1^{a}$ Regla castellana recomienda que el destino de tod aquello que ganaren en tierra de moros la part de sos cuerpos den por catiuos sacar de tierra de moros (Lomax, 1965, doc. 1, n. $\left.{ }^{\circ} 35: 226\right)$. Sobre la forma commo han de sacar los captivos los comendadores de los hospitales de Toledo e Cuenca e Alarcon, véase Establecimientos de 1480-1481, tit. VIII (BN, Ms. 8.582, fol. 244r). En los Establecimientos de 1310 se recuerda que era necesaria la licencia del maestre para realizar aquellas transacciones (Aguado de Cordova et alii, 1719, art. 21: 263). Y parecida disposición se mantiene hasta el siglo XVI (Ruiz de Morales, 1998, cap. 26: 178). Por otro lado, los Establecimientos de 1274 establecen límites a los comendadores para disponer del botín de caualgadas y aventuras (BN, Ms. 8.582, n. ${ }^{\circ} 31$, fols. 48r-48v).

86 Leclercq, 1958: 353.

87 Establecimientos de 1275, n. ${ }^{0} 1$ y 9 (BN, Ms. 8.582, fols. 66v-67r).

88 Matellanes, 1993: 126, sostuvo que las primeras se fundaron a iniciativa de los propios freires, mientras que los segundos contaron con el mecenazgo nobiliario. 
próximas a ella ${ }^{89}$, se encargaron asimismo de dotar puestos de campaña avanzados, que en este caso sí que acompañarían a las tropas en sus acciones ${ }^{90}$. Dichos establecimientos hospitalarios contaron con físicos para los dolientes (...) incluidos los que fueren en recoa, y sus responsables estaban exentos de participar con caballos o armas en dichas huestes, para dedicarse por completo al cuidado de enfermos y heridos ${ }^{91}$.

Como cabría esperar, otro capítulo esencial del contenido de los establecimientos santiaguistas se centra en diferentes disposiciones para la administración eficiente y el control de sus fortalezas. En primer lugar, se puede hablar de una parte de la normativa que trata de la formación de ese patrimonio; sobre las condiciones de entrega del mismo a tenentes o baylios que fueran hijosdalgo y caballeros; en relación con la supervisión de dichas entregas por parte del maestre y el comendador mayor ${ }^{92}$; o acerca del especial tratamiento de los castillos fronteros, que no debían ser depositados en manos de seglares ni alcaides ${ }^{93}$, sino preferentemente ser custodiados por freires que además residieran en ellos ${ }^{94}$.

Hay algunas disposiciones, por otro lado, dedicadas a velar por el mantenimiento de las muchas fortificaciones en manos de la orden de Santiago, o informativas acerca de los recursos necesarios para su funcionamiento operativo; en torno al estricto control de sus entradas y salidas; o sobre las posibles guarniciones que los protegerían ${ }^{95}$. E igualmente, podemos aludir en este punto a otro eficaz mecanismo de control de los castillos de la orden, al que también se refieren los textos normativos. Nos referimos al que se articuló a través de las inspecciones

89 El hospital de Toledo fue fundado para la redención de cautivos, sobre un antiguo establecimiento creado para curar los heridos en la guerra, dice Rades. Pero no fue el único, ya que la milicia dotó, en las primeras décadas de su existencia, otros centros asistenciales en Ávila, Talavera, Cuenca, Alarcón y en Villamartín (Rades y Andrada, 1572: fols. 18r, 18v, 19r y 20r, Chronica Santiago). A este respecto véase Iradiel, 1981; Madrid y Medina, 1999, 2004 y 2014; García Carpintero, 2018.

90 Los comendadores que fueren sobre las enfermerias studien se a complir que quando las huestes entraren a tierra de moros e ellos entren con aquel appareiamiento con el qual a los freyres e a los otros fieles de la hueste si ad algunos conteciere enfermar, que ellos les puedan aministrar assi como conuiene en tan estrecho logar $\left(1^{a}\right.$ Regla castellana, $\mathrm{n}^{\circ}$ 39, Lomax, 1965, doc. 1: 226). También en Ruiz de Morales, 1998, cap. 28: 178-179.

91 Establecimientos de 1310, art. 6 (Aguado de Cordova et alii, 1719: 261); Establecimientos de 1274, n. ${ }^{\circ} 17$ (BN, Ms. 8.582, fol. 47r).

92 Recordemos, por ejemplo, que Ningund freyre non sea osado de resçibir castillo de mano de Rey nin de otro ninguno sin liçençia del maestre o del comendador mayor, tal y como recogen los Establecimientos de 1251, n. ${ }^{\circ} 7$ (BN, Ms. 8.582, fol. 56v) y los de 1440, n. $^{\circ} \mathrm{X}$ (Ostos, 2008: 249-250). Del mismo modo que se dispusieron estrictas condiciones para el traspaso de cualquier fortaleza que perteneciera a una encomienda, que solo podría ser recibida personalmente por el maestre o el comendador (Establecimientos de 1252, n. ${ }^{\circ}$ 1, BN, Ms. 8.582, fol. 62r).

93 Acerca de reiterados incumplimientos de esta normativa: Ayala, 2001: 558.

94 Establecimientos de 1251, n. 22 (BN, Ms. 8.582, fol. 57v); Establecimientos de 1259, n. ${ }^{\circ} 8$ (BN, Ms. 8.582, fol. 64v); Establecimientos de 1274, n. ${ }^{\circ}$ 2, 10 y 23 (BN, Ms. 8.582; fols. 45v, 46r y 47v); Establecimientos de 1275 , n. ${ }^{\circ} 11$ (BN, Ms. 8.582, fol. 67v); Establecimientos de 1310, arts. 9, 10 y 16 (Aguado de Cordova et alii, 1719: 262); los Establecimientos de 1440, n. $^{\circ}$ XLIII y LII (Ostos, 2008: 268 y 275) introducen la disposición que obligaba a los comendadores de castillos de la frontera a no abandonarlos sin licencia del maestre; la cual se mantiene en los de 1480-1481 (BN, Ms. 8.582, tit. XVIII); y se concreta en un periodo de, al menos, cuatro meses de estancia en los mismos, según el interrogatorio de las visitas que se recoge en las últimas versiones de la regla (Ruiz de Morales, 1998: 244) y en la ([Primera] Historia de la Orden (Parra y Orozco, 1978, cap. XX: 351). Al final del periodo estudiado los tenentes de las fortalezas, además de ser hombres del hábito y Orden, y que sean hijosdalgo, debían ser personas generosas (Ruiz de Morales, 1998, tit. 6, caps. 6 y 17 , y tit. 10 , cap. 5: $325,333-334$ y 357-358).

95 Acerca de la penitencia impuesta a los freires en el caso de que alguno en defension de los castiellos de la casa o en otras cosas que el maestro manda defender por uentura matar omne, véase $1^{a}$ Regla castellana, n. ${ }^{\circ} 62$ (Lomax, 1965, doc. 1: 229). Acerca del celo con el que se disponía la vigilancia de los castillos de la orden, los Establecimientos de 1251 revelan que sus visitantes temporales, aunque fueran freires o incluso comendadores de otros lugares, no podían salir de la villa o del castillo al menos de liçençia del comendador, y recuerdan las penas para los hermanos que abandonaran un castillo de la orden hostigados por los moros (BN, Ms. 8.582, n. ${ }^{\circ} 30$ y 53, fol. 58v y 61). Los Establecimientos de 1274 informan, por su parte, de las guarniciones de los castillos fronteros, formadas por omnes de pie e de cauallo los que menester ovieren e podieren mantener (BN, Ms. 8.582, $\mathrm{n}^{\circ} 22$, fol. $\left.47 \mathrm{v}\right)$. 
regulares impuestas por el régimen de visitas, un sistema de vigilancia disciplinario, pero también patrimonial, al que estaban sometidas todas las casas de la orden, que fue aplicado con especial celo respecto a la conservación de sus arquitecturas defensivas ${ }^{96}$, así como al estado de revista de las enfermerías y hospitales de la institución ${ }^{97}$.

Por último, una parte de la documentación normativa santiaguista trata de asegurar el control jurisdiccional de tan importante recurso militar, apelando a ciertos derechos vinculados especialmente con ese patrimonio. Hablamos, en suma, del homenaje vasallático debido y exigido por estas fortificaciones, de la imposición de severas penas para quienes se rebelaran desde una fortaleza de la orden contra el maestre, así como la preocupación general por mantener sujetos estos inmuebles a la autoridad maestral. Un control que se manifiesta, a su vez, en las mencionadas visitas periódicas y en el juramento que todos los tenentes y comendadores debían prestar por los castillos que tenían encomendados, estando obligados a dejar entrar en ellos al maestre y a entregárselos si fueran reclamados ${ }^{98}$.

\section{CONCLUSIONES}

A pesar de que este trabajo surgió con una intención recopilatoria y un tono casi taxonómico, acerca de los testimonios que la dispersa normativa de las dos órdenes militares hispanas más importantes ofrece en relación a la guerra, no queremos cerrar el texto sin exponer algunas consideraciones finales, que sirvan de conclusión al mismo.

Para empezar, nos parece necesario subrayar el hecho de haber trabajado sobre un corpus legislativo con unas características de heterogeneidad a diferentes niveles, que han de ser tenidas en cuenta. Por un lado, los emisores de estas reglas, definiciones o establecimientos fueron variados. Desde la autoría colegiada de los capítulos generales, a las emisiones protagonizadas por maestres legisladores, abades y visitadores, o las confirmaciones de los pontífices, quienes pudieron imprimir su particular punto de vista e intereses sobre textos de elaboración colectiva. En cada caso, estos productores de normativa destinada al gobierno de las órdenes y a regular, entre otras, sus actividades militares, fueron distintos y posaron su atención en cuestiones diversas.

No debe sorprender, por tanto, constatar que la mayoría de las reglas y definiciones calatravas fueran promovidas por los abades de Morimond, o sus delegados, monasterio del que dependía disciplinariamente la orden y a través del que se articulaba su vínculo orgánico con Cîteaux ${ }^{99}$; que en algún caso fuera directamente el capítulo general del Císter el que lo hiciera, como ocurrió a finales del siglo XIII, respondiendo así a los procuradores enviados por la orden ${ }^{100}$; o que dichas intervenciones estuvieran muy habitualmente motivadas por tensiones

${ }^{96}$ Los establecimientos modernos de la orden regularon la acción de los visitadores, que debían recorrer los señoríos santiaguistas según la forma antigua y que se acostumbra en nuestra Orden, viendo los castillos y casas della, para determinar las reparaciones que correspondía realizar a los comendadores o al maestre (Ruiz de Morales, 1998, tit. 2, cap. 1: 259). Sobre la importancia de estos textos para el conocimiento de la arquitectura fortificada de la orden de Santiago, véase Palacios Ontalva, 2000.

${ }^{97}$ Establecimientos de 1275, n. $^{\circ} 1$ y 9 (BN, Ms. 8.582, fols. 66v-67r).

${ }^{98}$ Los Establecimientos de 1440, n. ${ }^{\circ}$ XXV y XLIII, recuerdan Commo el freyre que non diere la fortaleza o castillo que touiere al maestre quando ge lo demandare, que sea lançado de la Orden e nunnca en ella aya fortaleza, e igualmente establece el homenaje obligatorio para formalizar las entregas de este patrimonio (Ostos, 2008: 258 y 268). Véase también: Ruiz de Morales, 1998, tit. 10, cap. 4: 357; Orozco y Parra, 1978, cap. XX: 351.

99 Sobre el interés especial de los abades de Morimond por anudar fuertes vínculos con sus filiae hispanos: Lomax, 1961: 488; O’Callaghan, 1975a: 48-49; Ayala, 2000: 545-546; Josserand, 2009.

100 Oliveira, 2015: 118 y 2020: 11 . 
y problemas de disciplina entre los freires, que la casa madre pretendía atajar ${ }^{101}$. Tampoco es extraño que en la más secular e independiente orden de Santiago sean, sin embargo, los maestres quienes protagonicen esas iniciativas, algunas de ellas especialmente notables, como la serie de establecimientos emitidos en diversos capítulos generales con el impulso de Pelayo Pérez Correa, que aupó la figura maestral a una consideración casi monárquica, y contribuyó a imprimir a la orden rasgos de señorialización particularmente evidentes. Pero si hablamos de la cristalización de esta normativa no es en modo alguno extraño encontrar entre los pontífices confirmantes de los más primitivos textos a papas como Alejandro III, el efímero pero comprometido Gregorio VIII ${ }^{102}$ o el gran Inocencio III, implicados absolutamente con la idea de la cruzada, de la que las órdenes eran principales impulsoras y herramientas para su materialización a ambos lados del Mediterráneo.

La normativa tratada es, asimismo, una legislación acumulativa y en constante revisión, que se sedimenta en preceptos de larga vigencia temporal o se renueva en función de procesos internos de las instituciones que, igualmente, merece la pena subrayar. La constatación de esta idea se podría ilustrar a partir del cotejo de los sintéticos articulados de las emisiones legislativas iniciales, respecto a los textos que circularon durante los siglos modernos, en los que se fueron incorporando a veces sustanciales añadidos, que completaron las respectivas reglas hasta dar forma a sus versiones impresas y más difundidas.

Como ocurre con cualquier norma legal, hemos de tener en cuenta, además, que su contenido no se puede separar del momento histórico en el que surgen, el cual puede marcar la aparición u olvido de determinados preceptos jurídicos. La normativa se acompasa, pues, con la coyuntura política y social del momento, como ocurre con las Definiciones de Salvatierra, dadas a comienzos del siglo XIII en un momento especialmente sensible para la orden de Calatrava, necesitada de refuerzo institucional y disciplinario tras la debacle de Alarcos. Por otro lado, son reiteradas o se hicieron recurrentes en momentos de especial turbulencia interna, las disposiciones en relación con la elección y obediencia debida al maestre, acerca de los duros castigos para quienes se insubordinaran contra su autoridad o en relación con el control de los castillos de las órdenes ${ }^{103}$. Del mismo modo que la progresiva señorialización que vivieron estas instituciones, se hizo visible también en normas jurídicas precisas que sancionaron, por ejemplo, unas endurecidas condiciones para profesar en ellas, evidentes a partir de la segunda mitad del siglo XIII. E igualmente se percibe este correlato entre el contexto histórico y las emanaciones legales de las órdenes cuando notamos un cambio general de mentalidad en las milicias, desde comienzos del siglo XIV, encaminado a su secularización, que se plasmó en normas destinadas a mitigar la relajación de los votos monásticos que se empezaba a percibir entonces ${ }^{104}$.

En otro sentido, pese al gran número de elaboraciones legislativas generadas por las órdenes en las que hemos rastreado disposiciones tocantes a su vocación y actividades militares, la

101 Josserand, 2009: 233-234

102 Antes de ser elevado al solio pontificio, Alberto de Morra redactó para los santiaguistas desplazados a Roma la primera bula de confirmación de la orden de Santiago que suscribiera Alejandro III, así como la propia regla que la acompaña, y su elocuente e historiográfico prólogo (Ferrari, 1960).

${ }^{103}$ Como acertadamente fue sugerido, no parece una casualidad que, tras el problemático y cuestionado comienzo del maestrazgo de García López de Padilla (1297-1336), concretamente en 1304, fueran promulgadas unas definiciones especialmente duras contra quienes conspiraran o se rebelaran contra el maestre (Ayala, 1999: 74; Difiniciones de 1304, n. ${ }^{\circ}$ 9-11, O’Callaghan, 1975b: 264-265). Ni extraña la coincidente preocupación de Pelayo Pérez Correa por mantener controladas las fortalezas de la orden, que evidencian varios artículos de los establecimientos que impulsó, así como otros posteriores que recuerdan que en aquel tiempo vino grand detrimento por los caualleros de nuestra Orden en aquella sazón, que eran de grand linaje, non le querer dar las fortalezas que tenían quando ge las demendauan el dicho maestre e avn al rey don Alfonso, que estonçes reynaua, fijo del rey don Fernando, grand deseruiçio, segund en la Corónica del dicho maestre se cuenta (Ostos, 2008: 258).

104 Josserand, 2009: 234-237. 
cantidad de evidencias detectadas son realmente pocas o se alude a ellas de forma tangencial. En comparación, sin embargo, hay otras preocupaciones más ampliamente representadas en las reglas, como eran las normas de conducta y vida comunitaria dadas a los hermanos, las referidas a la separación de poderes entre maestres y priores o los procedimientos para la elección de estas y otras dignidades, así como los asuntos destinados a la corrección de posibles discordias, particularmente las derivadas del reparto de los bienes y rentas en su seno ${ }^{105}$.

Los datos son elocuentes y de los 92 artículos de la primera Regla castellana, poco más de una docena aluden a la guerra como actividad o a los medios para llevarla a cabo (el 13\% de su contenido); de los 53 artículos de los Establecimientos de 1251, solo 10 tratan el tema de algún modo (cerca del 19\% de ellos); apenas 12 de los 72 de 1440 (el 16\%); y solo 4 de los 47 promulgados en 1480-1481 (en torno al 8\%); siendo los conocidos Establecimientos de 1274 donde la proporción es mayor y suman 18 disposiciones de las 34 que los componen (es decir, más del 50\%), lo que de nuevo nos pone sobre la pista del maestre Pérez Correa, tan gran dirigente político y legislador, como implicado caudillo militar.

Estas cifras suponen un claro contraste con la enorme actividad bélica que desarrollaron dichas instituciones y su presencia en todas las movilizaciones y escenarios posibles del periodo. Lo que implica necesariamente una reflexión acerca de la asimetría entre su intensa y esencial participación en la guerra, y la aparente falta de una regulación minuciosa sobre ella, ya que solo se abordan con cierto detalle algunas cuestiones, como la mencionada obediencia debida al maestre en tanto que máxima autoridad en el plano civil, religioso y también en el campo de batalla, o en relación con diferentes aspectos sobre la posesión, mantenimiento y control jurisdiccional de sus fortificaciones. Llama la atención, sin embargo, la ausencia casi total de interés por otros asuntos de los que apenas podemos espigar o deducir algunos datos. Nos referimos, por ejemplo, a referencias precisas sobre la dirección de las operaciones y los cuadros de mando de las milicias de las órdenes; acerca de la participación de los vasallos de sus jurisdicciones en las acciones militares; en torno al desarrollo de las mismas, la disposición táctica de sus efectivos, recomendaciones operativas concretas o rasgos que denoten alguna especialización militar de los hermanos; o sobre la formación y entrenamiento militar de los freires.

Cabría pensar que estos aspectos están ausentes de las formae vivendi y las definiciones calatravas por la identidad eclesiástica de sus emisores y la tradición e inclinación monástica de la institución, pero la realidad es que tampoco son más frecuentes en los establecimientos santiaguistas. Podríamos asumir, por otro lado, que esta normativa estuviera más dedicada a regular la vocación religiosa de los hermanos que su carisma castrense, más vinculado a la tradición y códigos caballerescos a los que también eran fieles, pero ninguna explicación resulta del todo satisfactoria para iluminar un desequilibrio en la información, interesante en sí mismo, que invita a indagar más sobre el compromiso militar de las órdenes a partir de estas y otras fuentes.

\section{BIBLIOGRAFÍA}

Aguado de Cordova, A. F.; Alemán y Rosales, A. A. y López Agurleta, J. (1719): Bullarium Equestris Ordinis S. Iacobi de Spatha. Madrid, Juan de Ariztia.

Ayala, C. de (1996): «Órdenes Militares hispánicas: Reglas y expansión geográfica». Los Monjes Soldados, los Templarios y otras Órdenes Militares, Codex Aquilarensis, 12: 57-86.

${ }^{105}$ A estas últimas se dedican una cuarta parte de los artículos de las Definições de finales del siglo XIII (Oliveira, 2015: 124 y 2020: 11).

Gladius, XL (2020), pp. 113-131. ISSN: 0436-029X; eISSN: 1988-4168. https://doi.org/10.3989/gladius.2020.05 
Ayala, C. de (1998): «The Sergents of the military order of Santiago», H. Nicholson (publ.), The military orders. 2. Welfare and warfare, Aldershot, Ashgate: 225-233.

Ayala, C. de (1999): «Un cuestionario sobre una conspiración. La crisis del maestrazgo de Calatrava en 1311-1313». Aragón en la Edad Media, XIV-XV, Homenaje a la profesora Carmen Orcástegui Gros. Zaragoza: 73-89.

Ayala, C. de (2000): «Órdenes militares castellano-leonesas y benedictinismo cisterciense. El problema de la integración (ss. XII-XIII)». Unanimité et diversité cisterciennes. Filiations-Réseaux-Relectures du XII e au XVII siècle, Actes du $4^{e}$ Colloque International du CERCOR. Saint Étienne: 525555.

Ayala, C. de (2001): «Las fortalezas castellano-leonesas de las órdenes militares. Problemas de control político y financiación (siglos XII-XIV)», I. C. Ferreira Fernandes (ed.), Mil anos de fortificações na Península Ibérica e no Magreb (500-1500). Actas do Simposío internacional sobre castelos (Palmela, 2000). Lisboa, Colibrí: 549-569.

Ayala, C. de (2003): Las órdenes militares hispánicas en la Edad Media (siglos XII-XV). Madrid, Marcial Pons y Latorre.

Ayala, C. de (2006): «Tenencias y retenencias de fortalezas de órdenes militares», J. V. Cabezuelo (ed.), Alcaidias y fortalezas en la España medieval. Alcoy, Marfil: 193-207.

Ayala, C. de (2007): «Guerra y órdenes militares. Problemas de organización militar y eficacia bélica», R. Izquierdo y F. Ruiz (ed.), Actas del Congreso, Tierra del Quijote. Tierra de Órdenes Militares. Ciudad Real, Junta de Comunidades de Castilla-La Mancha y Fundación Quijote, IV Centenario: 229-257.

Ayala, C. de (2009a): «Nuevos tiempos, nuevas ideas», A. Madrid y Medina y L. R. Villegas (eds.), El nacimiento de la orden de Calatrava. Primeros tiempos de expansión (siglos XII y XIII), Actas del I Congreso Internacional de la Orden de Calatrava. Almagro, Instituto de Estudios Manchegos: 9-56.

Ayala, C. de (2009b): «Los inicios de la Orden de Calatrava y la monarquía castellana», R. Torres y F. Ruiz Gómez (eds.), Órdenes Militares y construcción de la sociedad occidental (Siglos XII-XV). Madrid, Sílex Universidad, 223-266.

Benito Ruano, E. (1978): «Establecimientos de la Orden de Santiago en el siglo XIII», Estudios Santiaguistas. León, Colegio Universitario: 173-184.

Demurger, A. (2005): Caballeros de Cristo: templarios, hospitalarios, teutónicos y demás órdenes militares en la Edad Media (Siglos XI a XVI). Granada, Universidad de Granada y Universitat de València.

Ferrari, A. (1960): «Alberto de Morra, postulador de la Orden de Santiago y su primer cronista». Boletín de la Real Academia de la Historia, 146: 63-139.

Forey, A. (1986): «Novitiate and Instruction in the Military orders during the Twelfth and Thirteenth Centuries». Speculum, 61: 1-17.

Forey, A. (1992): The Military Orders. From the twelfth to the Early fourteenth centuries. Londres, Macmillan.

Forey, A. (2015): «Visitations in the military orders during the twelfth and thirteenth centuries», Viator, 46 (3): 95-122.

Gallego Blanco, E. (1971): The Rule of Spanish Military Order of St. James (1170-1493). Leiden.

García Carpintero, J. (2018): «La hospitalidad santiaguista a finales de la Edad Media: el proyecto de reconstrucción del Hospital de Alarcón». Espacio, Tiempo y Forma. Serie III, Historia medieval, 31: 343-376. https://orcid.org/https://doi.org/10.5944/etfiii.31.2018.20607

Iradiel Murugarren, P. (1981): «Bases económicas del Hospital de Santiago de Cuenca: Tendencias del desarrollo y estructura de la propiedad agraria». Anuario de Estudios Medievales, 11: 181-246.

Jiménez de Rada, R. (1987): Historia de Rebus Hispaniae sive Historia Gothica, J. Fernández Valverde (ed.). Corpus Christianorum. Continuatio Mediaevalis, LXXII, Turnhout, Brepols.

Josserand, Ph. (2004): Église et pouvoir dans la péninsule Ibérique. Les ordres militaires dans le royaume de Castille (1252-1369). Madrid, Casa de Velázquez. https://books.openedition.org/ cvz/3058\#bodyftn6

Josserand, Ph. (2005): «D'un couvent l'autre. L'abbaye de Morimond et les ordres militaires hispaniques de filiation cistercienne au Moyen Âge», G. Viard (ed.), L'abbaye cistercienne de Morimond. Histoire et rayonnement. Langres: 335-353. 
Josserand, Ph. (2009): «Vientos de cambio: las transformaciones de la orden de Calatrava a partir de finales del siglo XIII a través de la normativa cisterciense», A. Madrid y Medina y L. R. Villegas (eds.), El nacimiento de la orden de Calatrava. Primeros tiempos de expansión (siglos XII y XIII), Actas del I Congreso Internacional de la Orden de Calatrava. Almagro, Instituto de Estudios Manchegos: 225-238.

Leclercq, J. (1958): «La vie et la prière des chevaliers de Santiago d'après leur Règle primitive». Liturgica, 2: 347-357.

Linage Conde, A. (1981): «Tipología de la vida religiosa en las Órdenes Militares». Anuario de Estudios Medievales, 11: 33-58.

Lomax, D. (1961): «Algunos estatutos primitivos de la Orden de Calatrava». Hispania, 21: 483-494

Lomax, D. W. (1965): La Orden de Santiago (1170-1275). Madrid, CSIC.

Madrid y Medina, A. (1999): «La hospitalidad en las Ordenes Militares españolas». F. J. Campos y Fernández de Sevilla (coord.), Lux Hispaniarum: estudio sobre las Órdenes Militares. Madrid, Real Consejo de las órdenes militares: 237-262.

Madrid y Medina, A. (2004): «Los comienzos de la hospitalidad santiaguista: el Hospital de Ávila». Espacio, Tiempo y Forma. Serie III, Historia medieval, 17: 371-380. https://doi.org/10.5944/etfiii.17.2004.3707

Madrid y Medina, A. (2005): «Establecimientos de don Enrique de Aragón y don Alonso de Cárdenas». Revista de las Ordenes Militares, 3: 163-256.

Madrid y Medina, A. (2014): «El desaparecido hospital de los Caballeros de Santiago de Toledo». Revista de la CECEL, 14, ejemplar dedicado a Patrimonio rescatado: 47-70.

Martín, J. L. (1974): Orígenes de la Orden Militar de Santiago, 1170-1195. Barcelona, CSIC.

Matellanes, J. V. (1993): «La hospitalidad en la Orden de Santiago: un proyecto ideológico o económico (1170-1350)». Stvdia Historica. Historia Medieval, 11: 125-140.

Medrano, G. de (1627): La Regla y Establecimientos de la Cavalleria de Santiago del Espada, con la Historia del principio della. Madrid.

O'Callaghan, J. (1969): «Hermandades between the Military Orders of Calatrava and Santiago during the Castilian Reconquest, 1158-1252». Speculum, 44 (4): 609-618.

O'Callaghan, J. (1975a): «The Affiliation of the Order of Calatrava with the Order of Cîteaux», The Spanish Military Order of Calatrava and its Affiliates. Londres, Variorum Reprints, I: 161-193, 3-59 y 255-292.

O'Callaghan, J. (1975b): «The earliest 'Difiniciones' of the Order of Calatrava, 1304-1382», The Spanish Military Order of Calatrava and its Affiliates. Londres, Variorum Reprints, VII: 255-284.

O'Callaghan, J. (1975c): «'Difiniciones' of the Order of Calatrava enacted by abbot William II of Morimond», The Spanish Military Order of Calatrava and its Affiliates. Londres, Variorum Reprints, IX: 231-268.

O’Callaghan, J. (1996a): «La Vida de las Órdenes Militares de España según sus estatutos primitivos», R. Izquierdo y F. Ruiz Gómez (coords.), Alarcos 1195. Actas del Congreso Internacional Conmemorativo del VIII Centenario de la batalla de Alarcos, Cuenca, Universidad de Castilla-La Mancha: 7-29.

O’Callaghan, J. (1996b): «Las definiciones de la Orden de Calatrava, 1383-1418». En la España Medieval, 19: 99-124.

Oliveira, L. F. (2015): «Em torno da normativa de Calatrava: Umas Definições inéditas de finais do século XIII», J. Alburquerque Carreiras y C. de Ayala Martínez (eds.), Cister e as Ordenes Militares na Idade Média. Guerra, Igreja e Vida Religiosa. Tomar, Asociação Portuguesa de Cister: 103-136.

Oliveira, L. F. (2020): «De volta à normativa da Ordem de Calatrava: Novo testemunho das Definições de finais do século XIII». En la España Medieval, 43: 9-26.

Orozco, P. de y Parra, J. de la (1978): [Primera] Historia de la Orden de Santiago. D. Angulo, (prólogo) y Marqués de Siete Iglesias (introducción, transcripción, notas y apéndice). Badajoz, Institución 'Pedro de Valencia'.

Ortega y Cotes, I. J.; Álvarez de Baquedano, F. y Ortega Zúñiga y Aranda, P. (1761): Bullarium Ordinis Militiae de Calatrava. Madrid, Antonio Marín.

Ostos Salcedo, P. (2008): La Orden de Santiago y la escritura. El valor de la comunicación escrita en una orden militar. Los Establecimientos de 1440. León, Universidad de León Secretariado de Publicaciones. 
Palacios Ontalva, J. S. (2000): «Los libros de visitas de la orden de Santiago: fuente para una historia de la arquitectura militar». Actas del Tercer Congreso Nacional de Historia de la construcción. Sevilla, Instituto Juan de Herrera, Vol. II: 751-760.

Palacios Ontalva, J. S. (2018): «Una aproximación al concepto de 'lanza' en relación a las órdenes militares», I. C. Ferreira Fernandes (coord.), Entre Deus e o Rei. O mundo das Ordens Militares. Palmela, Município de Palmela y GesOS, vol. 1: 297-320.

Rades y Andrada, F. de (1572): Chronica de las tres Órdenes y Cauallerias de Santiago, Calatraua y Alcántara. Toledo, Juan de Ayala.

Rodríguez-Picavea Matilla, E. (2007): «El proceso de aristocratización de la orden de Calatrava (siglos XIII-XV)». Hispania Sacra, 59/120: 493-535.

Rodríguez-Picavea Matilla, E. (2008): Los monjes guerreros en los reinos hispánicos: las órdenes militares en la Península Ibérica durante la Edad Media. Madrid, La Esfera de los libros.

Ruiz de Morales y Molina, A. (1998): La regla y establecimiento de la Orden de Cauallería de Santiago del Espada, con la hystoria del origen y principio della, edición, estudio introductorio, notas e índices de M. ${ }^{a}$ I. Viforcos Marinas, J. Paniagua Pérez y J. Domínguez Domínguez. León, Universidad de León.

Ruiz Gómez, F. (2000): «La hueste de las Ordenes Militares», en R. Izquierdo y F. Ruiz Gómez (coords.), Las órdenes militares en la Península Ibérica. Cuenca, Ediciones de la Universidad de Castilla-La Mancha, vol. 1, 403-436.

Sastre Santos, E. (1982): La Orden de Santiago y su Regla. Madrid, Universidad Complutense.

Villegas, L. R. (1991): «Las estructuras de poder de la orden de Calatrava. Una propuesta de análisis». Historia. Instituciones. Documentos, 18: 467-504.

Recibido: 13-08-2019

Aceptado: 14-04-2020 